he was lying this sound was higher in pitch and accentuated. A systolic murmur was present but not conducted, and also a mid-diastolic murmur localized to the apex. This was especially obvious after exertion. A well-compensated slight mitral stenosis was therefore present. This man would be unfit for any service exposing him to physical stress. In special circumstances he might be available for clerical or other fairly sedentary work. But any recrudescence of the active rheumatism might result in a heavy pensions liability to the country; for the subsequent illness might well be prolonged, with remissions, for fifteen to twenty years.

Case 4.-A man aged 32, $6 \mathrm{ft} .4$ in. in height and well built in proportion, was found to have the murmur of aortic regurgitation. He had always been healthy, and had played games normally at school. On examination the presence of aortic regurgitation was confirmed, but the associated leak was insignificant. This was proved by two facts: first, the diastolic pressure was not lowered $(126 / 72)$; secondly, there was little cardiac enlargement, the apex beat being in the fifth space and the orthodiagraphic diameter of the heart being only about $1 \mathrm{~cm}$. above normal. This man had the definite promise of a surveying job in the artillery, for which he was fitted by his civil experience. He was therefore passed as fit.

Case 5.-A man aged 24 had had rheumatic fever two years previously. Since then he had worked as a coal-miner and had remained free from symptoms. On examination aortic regurgitation was found. Here again there was no significan leak, the blood pressure being normal $(138 / 70)$ and the apex beat being in the fifth space in the mid-clavicular line. This man was rejected; for the risk of a second attack of acute rheumatism was greater since the first had been so recent, and he had no special qualifications which would enable him to be useful in a more sheltered job. Life in the ranks with exposure to weather and physical fatigue would provide too great a risk of another attack of acute rheumatism.

Case 6.- - A man aged 26 had suffered from acute rheumatism at the age of 11 . Since then he had been well, his recent work entailing heavy lifting in a timber yard. He had played games until the time of examination. He was found to have some hypertrophy of the left ventricle, the apex beat being forcible and just external to the mid-clavicular line. A systolic thrill was felt at the aortic base, conducted into the vessels of the neck. This was coincident with a similarly conducted harsh systolic murmur, also audible at the apex. An early diastolic murmur was present at the aortic base, and at the apex, indicating some aortic regurgitation. This was slight, for the blood pressure was not changed (152/80). Aortic stenosis was thus the significant lesion. The man was rejected; for, although he had no symptoms at the time, the thickening and calcification of the aortic valve cusps and the neighbouring tissue is progressive, and it is likely to affect the coronary circulation, producing angina of effort or unexpected death, especially after heavy exertion. If the man was likely to be of great use to the military authorities in some physically sheltered and skilled position it might be safe to pass him, but a definite risk would thus be undertaken.

\section{Aids to Diagnosis}

Very little mention has been made in the above paragraphs of the use of radiological and electrocardiographic aids to diagnosis. Many cases can be accurately assessed without these, but in all cases of doubt their help is invaluable. The $x$-ray screen is of use especially in the diagnosis of early mitral stenosis and patent ductus arteriosus, and it is an invaluable method of measuring accurately the size of the heart by orthodiagraph. This single observation is the most valuable of all in deciding the presence or absence of organic disease. Although a few exceptions occur, it may be stated that a heart which is not enlarged is organically normal, and, on the contrary, every enlarged heart is organically abnormal. In the examination of healthy young adults the electrocardiograph is more helpful in analysing irregularities than in estimating myocardial changes. Therefore it is of less practical value than the $x$-ray screening apparatus in this particular group of cases.

\section{COLORIMETRIC STANDARDS FOR EMER- GENCY ESTIMATIONS OF CERTAIN CONSTITUENTS OF BLOOD AND C.S.F.}

\author{
BY
}

EARL J. KING, M.A., Ph.D.

Reader in Pathological Chemistry in the University of London

(From the British Postgraduate Medical School and the E.M.S. Pathological Service, Sector VI)

The determination of urea in blood is most easily carried out by conversion of the urea into ammonia by urease, followed by direct Nesslerization; that of non-protein nitrogen (N.P.N.) and plasma proteins by suitable digestion with sulphuric acid, whereby the whole of the contained nitrogen is converted into ammonia, followed by Nesslerization. The resulting yellowish-brown solution is compared with a suitable standard in a Duboscq or photoelectric colorimeter, or in a photometer. Such instruments are not always available to the clinician or to the pathologist working under emergency conditions.

With the purpose of providing a simple means of estimating these substances without the use of elaborate apparatus artificial coloured standards for comparison have been investigated. Such standards should be indistinguishable in day or artificial light from the "Nessleryellow" colour and should have a fair degree of permanency. To this end attempts have been made, first, to secure permanent suspensions of the yellowish-brown colloid produced with dilute ammonia and Nessler's reagent (these have not been satisfactory) ; and, secondly, to find a coloured substance or substances exhibiting a yellowish-brown tinge in solution which would appear sufficiently similar to most observers. Of the various substances tried a mixture of ferric chloride and cobalt chloride in hydrochloric acid solution has been the most satisfactory.

In the standards proposed the proportions and amount of ferric chloride and cobalt chloride have been so adjusted that the resultant mixtures have appeared indistinguishable from Nesslerized ammonia solutions in daylight and in artificial light. The comparisons have been made in test-tubes of standard bore $(5 \times 5 / 8$ in.) viewed in a comparator block against frosted glass and in a testtube rack against white paper. A standard ammonium chloride solution containing the equivalent of $0.01 \mathrm{mg}$. of $\mathrm{N}$ per $\mathrm{c.cm}$. was employed as a basis for the comparisons. This solution was used in varying amount with added water and $1 \mathrm{c} . \mathrm{cm}$. of Nessler's reagent in a total volume of $8 \mathrm{c.cm}$. This is the final volume of test and standard solutions in the micro-methods for blood urea, N.P.N., and plasma protein described by King et al. (1937), which are proposed for use with the permanent iron-cobalt standards. The numbers shown in the first column of Table I refer to the amount of nitrogen $(\mathrm{mg}$. N) present as Nesslerized ammonia in the volume of $8 \mathrm{c.cm}$. which is the equivalent in colour of the stated quantities of iron chloride and cobalt chloride contained in the same volume.

The standard values have been chosen to represent the concentrations most often encountered clinically. They are so spaced as to represent increments of 0.005 or $0.01 \mathrm{mg}$. $\mathrm{N}$, corresponding to 10 or $20 \mathrm{mg}$. of urea or N.P.N. per $100 \mathrm{c.cm}$. of blood. In the lower and middle range the values are spaced more closely in order to allow of more accurate estimation of plasma proteins. For total proteins the increments of $0.005 \mathrm{mg}$. $\mathrm{N}$ correspond to $0.78 \%$ protein. By careful matching intermediate values can be 
assigned, and it should hence be possible to gauge the concentration of protein to within $0.4 \%$. On the same basis it should be possible to measure fibrin to within $0.02 \%$ and albumin to within $0.2 \%$. Since globulin is estimated by the difference between total protein and

TABLE 1.-Composition of Permanent Standards

\begin{tabular}{c|c|c|c}
\hline $\begin{array}{c}\text { Standard Value } \\
\text { (N equivalent) } \\
\text { mg. }\end{array}$ & $\begin{array}{c}\text { c.cm. of } \\
\text { Ferric Chloride } \\
\text { Solution* }\end{array}$ & $\begin{array}{c}\text { c.cm. of } \\
\text { Cobalt Chloride } \\
\text { Solution* }\end{array}$ & $0.1 \mathrm{~N} \mathrm{HCl}$ \\
\hline 0.015 & 1.1 & 0.15 \\
0.02 & 1.4 & 0.27 \\
0.025 & 1.75 & 0.40 \\
0.03 & 2.1 & 0.55 \\
0.035 & 2.4 & 0.68 \\
0.04 & 2.75 & 0.80 \\
0.045 & 3.1 & 0.93 \\
0.05 & 3.4 & 1.05 \\
0.055 & 4.15 & 1.30 \\
0.06 & 4.7 & 1.55 \\
0.07 & 5.4 & 2.80 & \\
0.08 & 5.9 & 2.10 & \\
0.09 & $0.1 \mathrm{~N} \mathrm{HCl \text {added }}$ to make the \\
volume 8 c.cm. \\
\hline
\end{tabular}

* Ferric chloride solution: $10 \%$ (w./v.) $\mathrm{FeCl}_{3} .6 \mathrm{H}_{2} \mathrm{O}$ in $0.1 \mathrm{~N} \mathrm{HCl}-$-i.e., 10 grammes of the salt dissolved in enough $\mathrm{N} / 10$ hydrochloric acid to make $\stackrel{\text { a final volume of } 100}{\mathrm{CoCl}} \mathrm{l}_{2} .6 \mathrm{H}_{2} \mathrm{O}$ in $0.1 \mathrm{~N} \mathrm{HCl}$.

albumin the error may be additive, and at the most should be $0.6 \%$. For C.S.F. protein the increments of $0.005 \mathrm{mg}$. $\mathrm{N}$ correspond to $6 \mathrm{mg} . / 100 \mathrm{c} . \mathrm{cm}$. of protein, and halfincrements to $3 \mathrm{mg}$.

An alternative rapid method for plasma and C.S.F. proteins is also described.

The colour of iodine in ether solution is very much like that of the Nessler yellow. The estimation of sugar by a method in which the final determination is of liberated iodine should make it possible to estimate blood sugar by means of the permanent standards. The SchafferHartman procedure was easily adapted to this purpose. The intensity of the iodine colour is in inverse proportion to the amount of sugar: the more sugar there is present the more iodine will be used to reoxidize cuprous copper; therefore, the lower values in the permanent standards correspond to high sugar values, and the higher standards to low sugar values. The figures for blood sugar obtained in this way are, of course, only rough estimates of the true values, but they are close enough to be of clinical use. In practice it has been found that figures within 10 or $15 \mathrm{mg}$. of the known values of dilute sugar solutions or the determined values (by an accurate method) of blood filtrates can be obtained.

Haemoglobin is usually estimated by comparing the carboxyhaemoglobin pink colour produced when blood is treated with carbon monoxide or the yellowish-brown colour of acid haematin which is formed when blood is diluted with weak hydrochloric acid. The latter colour is very much like that of the ferric chloride-cobalt chloride standards. The similarity is increased by including a small amount of ferric chloride in the hydrochloric acid with which the blood is treated. The colours are best compared in a comparator block with the tubes placed behind frosted glass. With the procedure described the match is best for amounts of acid haematin corresponding to less than $80 \%$ haemoglobin. With larger amounts the colour of the acid haematin solution is somewhat browner than the standards, and the match is correspondingly more difficult. Several observers, however, will usually agree on the value assigned. Results within 5 to $10 \%$ of the values by the Haldane procedure are obtained.

\section{Methods of Analysis for Use with Permanent Standards}

Blood Urea. $-0.2 \mathrm{c.cm}$. of blood is diluted with $3.2 \mathrm{c.cm}$. of isotonic sodium sulphate $\left(3 \%\right.$ w. $/ v$. $\left.\mathrm{Na}_{2} \mathrm{SO}_{4} \cdot 10 \mathrm{H}_{2} \mathrm{O}\right)$.
A "knife point" (about $10 \mathrm{mg}$.) of Jack bean meal or half a urease tablet is added, and the mixture is kept warm for fifteen minutes-e.g., in a $37^{\circ}$ bath, a beaker of warm water, or in the waistcoat pocket. The proteins are precipitated by the addition of $0.3 \mathrm{c.cm}$. each of $10 \%$ w./v. zinc sulphate $\left(\mathrm{ZnSO}_{4} \cdot 7 \mathrm{H}_{2} \mathrm{O}\right)$ solution and of $\mathrm{N} / 2$ $\mathrm{NaOH}$. The mixture is centrifuged or filtered and $2 \mathrm{c.cm}$. of filtrate ( $\equiv 0.1 \mathrm{c.cm}$. blood) is treated with $5 \mathrm{c.cm}$. of water and $1 \mathrm{c.cm}$. of Nessler's reagent in one of the standard-bore test tubes. The colour is matched with the standards and the figure obtained (mg. N) multiplied by 2,140 -i.e., $\frac{100}{0.1} \times 2.14$-to give the mg. urea per $100 \mathrm{c.cm}$. C.S.F. urea may be estimated in the same way.

Non-protein Nitrogen. $-0.2 \mathrm{c.cm}$. of blood is added to $3.2 \mathrm{c} . \mathrm{cm}$. of water or isotonic sodium sulphate. $0.6 \mathrm{c.cm}$. of $25 \%$ trichloracetic acid is added*; the mixture is well shaken and is filtered after five minutes. $1 \mathrm{c.cm}$. of filtrate $(\equiv 0.05 \mathrm{c} . \mathrm{cm}$. blood) is heated with $0.2 \mathrm{c.cm}$. of $50 \%$ sulphuric acid (by vol.) until the mixture is brown. (The addition of a small piece of porous pot prevents " bumping.") A drop of $30 \%$ hydrogen peroxide is added and the heating is continued for four minutes. $5 \mathrm{c.cm}$. of water is added, and after thorough mixing $3 \mathrm{c.cm}$. of Nessler's solution. The figure obtained on matching with the standards is multiplied by $2,000-i . e ., \frac{100}{0.05}$-to give the mg. N.P.N. per $100 \mathrm{c.cm}$. of blood.

Plasma Total Protein : (1) By Difference with N.P.N.$0.2 \mathrm{c.cm}$. of plasma or serum is diluted to $10 \mathrm{c} . \mathrm{cm}$. with isotonic sodium sulphate. $0.2 \mathrm{c} . \mathrm{cm}$. of the mixture $(\equiv 0.004$ c.cm. plasma) is digested with $0.2 \mathrm{c.cm}$. of $50 \%$ sulphuric acid (as in the case of N.P.N.), diluted with $5 \mathrm{c.cm}$. of water, well shaken, treated with $3 \mathrm{c} . \mathrm{cm}$. of Nessler's solution, and the colour compared. The value $(\mathrm{mg}$. N) is multiplied by 25,000 -i.e., $\frac{100}{0.004}$-to obtain the total $\mathrm{N}$ per $100 \mathrm{c.cm}$. The N.P.N. value (as mg./100 c.cm.) is found for the plasma or serum, and is subtracted from the total $\mathrm{N} / 100 \mathrm{c.cm}$. $\dagger$ The resulting figure is divided by 1,000 and multiplied by 6.25 to obtain the number of grammes of total protein per $100 \mathrm{c.cm}$.-i.e., the percentage of protein.

(2) By Precipitation of the Protein. $-0.2 \mathrm{c.cm}$. of plasma or serum is diluted to $10 \mathrm{c.cm}$. Of the mixture $0.2 \mathrm{c.cm}$. ( $\equiv 0.004 \mathrm{c.cm}$. plasma) is diluted with $4 \mathrm{c.cm}$. of water in a pyrex centrifuge tube; $0.1 \mathrm{c.cm}$. of $10 \%$ zinc sulphate and $0.1 \mathrm{c.cm}$. of $\mathrm{N} / 2 \mathrm{NaOH}$ are added; the mixture is shaken and the precipitated proteins are spun down. The supernatant liquid is decanted off ; $0.2 \mathrm{c.cm}$. of $50 \%$ $\mathrm{H}_{2} \mathrm{SO}_{4}$ and a piece of porous pot are added. The digestion is carried out as described above. The figure (mg. N) obtained on comparing with the standards is multiplied by 156 -i.e., $\frac{100}{0.004} \times \frac{6.25}{1,000}$ to obtain the percentage of total protein.

Albumin. 0.2 c.cm. of plasma or serum is diluted to 5 c.cm. with $42 \%$ w. $/ \mathrm{v}$. $\mathrm{Na}_{2} \mathrm{SO}_{3} .7 \mathrm{H}_{2} \mathrm{O}$. The mixture is filtered after fifteen minutes from the precipitated globulin (Haslewood, 1940 ; Campbell and Hanna, 1937). $0.2 \mathrm{c.cm}$. of the filtrate ( $\equiv 0.008 \mathrm{c.cm}$. plasma or serum) is treated

* Alternatively, $0.3 \mathrm{c.cm}$. of $10 \%$ sodium tungstate and $0.3 \mathrm{c.cm}$. of $2 / 3 \mathrm{~N} \mathrm{H}_{2} \mathrm{SO}_{4}$ may be used for the deproteinization.

$\dagger$ If the mg. of blood urea per $100 \mathrm{c} . \mathrm{cm}$. be already known and be not grossly elevated it will be sufficiently accurate to subtract this figure from the total $N$ instead of performing the plasma N.P.N. estimation. In cases where there is no reason to suspect nitrogen retention the normal average N.P.N. figure for plasmanamely, $25 \mathrm{mg}$.-may be used. 
by either of the procedures for total protein. The following are the calculations entailed:

(1) By difference with N.P.N.:

$$
\begin{aligned}
& \text { mg. albumin } \mathrm{N}+\mathrm{N} . \mathrm{P} . \mathrm{N} .=\text { Reading } \times 12,500\left(\text { i.e., } \frac{100}{0.008}\right) \\
& \text { mg. albumin } \mathrm{N}=\text { (Reading } \times 12,500 \text { ) }- \text { N.P.N. } \\
& \% \text { albumin }=\frac{\text { mg. albumin } \mathrm{N} \times 6.25}{1,000} .
\end{aligned}
$$

(2) By precipitation of the albumin :

$$
\% \text { albumin }=\text { Reading } \times 78\left(\text { i.e., } \frac{100}{0.008} \times \frac{6.25}{1,000}\right)
$$

Globulin.-Total protein minus albumin.

Fibrin. $-0.1 \mathrm{c.cm}$. of plasma is diluted to $5 \mathrm{c.cm}$. with isotonic sodium chloride in a narrow tube. $0.1 \mathrm{c.cm}$. of $2.5 \%$ calcium chloride is added. The mixture is left to clot at $37^{\circ} \mathrm{C}$. The clot is collected on a thin glass rod; this is transferred to a test tube for digestion with $\mathrm{H}_{2} \mathrm{SO}_{4}$. The value obtained for the colour on matching with the standards is multiplied by $6.25-$ i.e., $\frac{i 00}{0.1} \times \frac{6.25}{1,000}$; the result is the percentage of fibrin.

C.S.F. Protein. -0.1 c.cm. of C.S.F. is digested with 0.2 c.cm. of $50 \%$ sulphuric acid as in the method for plasma total protein. The value obtained on comparing with the standards is multiplied by 1,000 -i.e., $\frac{100}{0.1}$ - to give the total $\mathrm{mg}$. $\mathrm{N}$ per $100 \mathrm{c.cm}$. C.S.F. The N.P.N. of the C.S.F. is estimated by digestion and Nesslerization of $1 \mathrm{c} . \mathrm{cm}$. of a $1: 10$ protein-free filtrate, equivalent to $0.1 \mathrm{c.cm}$. C.S.F. $(0.5 \mathrm{c.cm}$. of C.S.F. $+3.5 \mathrm{c.cm}$. of water $+1 \mathrm{c.cm}$. of $25 \%$ trichloracetic acid). The result is multiplied by 1,000 to give the N.P.N. (mg. per $100 \mathrm{c.cm}$. of C.S.F.). The N.P.N. is subtracted from the total $\mathrm{N}$ to give the $\mathrm{mg}$. protein $\mathrm{N}$ in $100 \mathrm{c.cm}$. This figure is multiplied by 6.25 to give the $\mathrm{mg}$. protein per $100 \mathrm{c.cm}$. C.S.F.

Estimation of Plasma and C.S.F. Protein by the Xanthoproteic Reaction.--When protein solutions are heated with nitric acid a yellow colour is produced. This is intensified by the subsequent addition of excess of alkali. The colour is very similar to that of the permanent standards. Its intensity increases with the amount of protein present, and the relation between colour and amount of protein is almost a straight line. The test is very easy to carry out and constitutes a simple method of estimating protein in solution. The results are in good agreement with those obtained by the $\mathrm{H}_{2} \mathrm{SO}_{4}$-digestion and Nesslerization procedure. One c.cm. of C.S.F. or of 1 in 20 diluted plasma (for example, $0.5 \mathrm{c.cm}$. plasma diluted to $10 \mathrm{c.cm}$. with isotonic sodium chloride or sulphate) is treated with $1 \mathrm{c.cm}$. of concentrated nitric acid. The mixture is heated rapidly to the boil, cooled immediately, and $2 \mathrm{c.cm}$. of sodium hydroxide $(40 \%)$ added. The colour produced is compared with the standards and the protein content derived from Table II.

TABLE II.-Protein Equivalents of Colorimetric Standards by Xanthoproteic Reaction

\begin{tabular}{l|c|c|c|c|c}
\hline Standards & $\begin{array}{c}\text { Mg. Protein } \\
\text { per 100 c.cm. } \\
\text { C.S.F. }\end{array}$ & $\begin{array}{c}\text { \% Protein } \\
\text { in Plasma }\end{array}$ & Standards & $\begin{array}{c}\text { Mg. Protein } \\
\text { per 100 c.cm. } \\
\text { C.S.F. }\end{array}$ & $\begin{array}{c}\% \text { Protein } \\
\text { in Plasma }\end{array}$ \\
\hline 0.015 & 50 & & 0.055 & 280 & 5.6 \\
0.020 & 70 & & 0.06 & 310 & 6.2 \\
0.025 & 95 & & 0.065 & 340 & 6.8 \\
0.03 & 120 & 2.3 & 0.07 & 370 & 7.4 \\
0.035 & 150 & 3.0 & 0.075 & 400 & 8.0 \\
0.04 & 185 & 3.7 & 0.08 & 430 & 8.6 \\
0.045 & 220 & 4.4 & 0.09 & 500 & 10.0 \\
0.05 & 250 & 5.0 & & & \\
\hline
\end{tabular}

Sugar. $-0.2 \mathrm{c.cm}$. of blood is diluted with $3.2 \mathrm{c.cm}$. of isotonic sodium sulphate and the proteins precipitated by $0.3 \mathrm{c.cm}$. of $10 \% \mathrm{w} . / \mathrm{v}$. sodium tungstate and of $7 \% \mathrm{w} . / \mathrm{v}$. copper sulphate $\left(\mathrm{CuSO}_{+} .5 \mathrm{H}_{2} \mathrm{O}\right)$. The mixture is centrifuged or filtered, and $2 \mathrm{c.cm}$. of filtrate is treated with 0.3 c.cm. of Harding's copper reagent (King et al., 1937) in a standard-bore test tube. The tube is heated in a boiling-water bath for ten minutes. It is then cooled and $0.5 \mathrm{c} . \mathrm{cm}$. each of $1 \%$ potassium iodide and of normal $\mathrm{H}_{2} \mathrm{SO}_{4}$ are added. $2 \mathrm{c.cm}$. of ether* is now added and the mixture well shaken. The iodine will be seen to have gone into the ether layer. The colour is compared with the standards, and the sugar value derived from Table III. If the colour obtained is less than the 0.02 standard the test is repeated with $1 \mathrm{c} . \mathrm{cm}$. of blood filtrate plus $1 \mathrm{c.cm}$. of water, and the result multiplied by 2. C.S.F. sugar may be estimated by the same procedure.

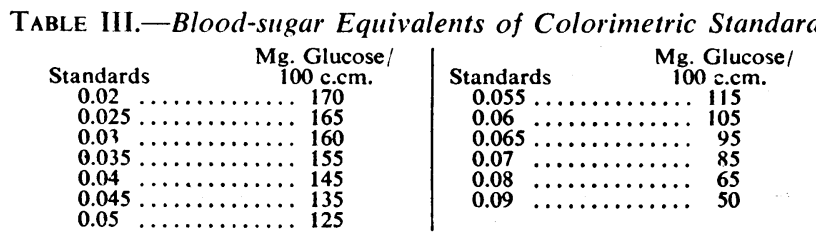

Haemoglobin. -0.02 c.cm. of blood is mixed with $5 \mathrm{c} . \mathrm{cm}$. of diluting fluid $(\mathrm{N} / 10 \mathrm{HCl}$ containing $1 \%$ ferric chloride, $\mathrm{FeCl}_{3} \cdot 6 \mathrm{H}_{2} \mathrm{O}$ ). The colour is matched with the standards after five minutes.

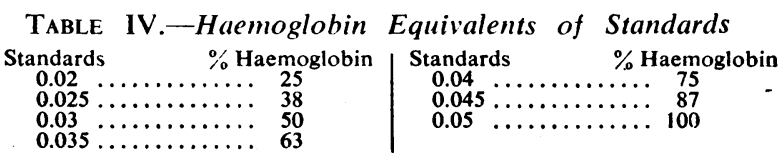

The percentage of haemoglobin is obtained from Table IV. If the colour is lower than that of the 0.02 standard the procedure should be repeated with $0.04 \mathrm{c.cm}$. of blood and the result divided by 2 . When the percentage of haemoglobin is of the order of 100 difficulty may be experienced by some observers in matching the test with the standards. By adding a further $5 \mathrm{c.cm}$. of diluting fluid a more dilute acid haematin solution will be obtained and the colour will now be easily matched with the standards; the value assigned is multiplied by 2 .

It is recommended that the results relating the standards to percentages of haemoglobin (Table IV) be plotted on graph paper. This will facilitate translation of the standard values assigned to haemoglobin tests, and particularly of intermediate values, into haemoglobin percentage. A straight-line relationship is obtained which cuts the standards axis at a point slightly below that corresponding to a standard containing the same concentration of iron as the diluting fluid.

\section{Summary}

Permanent artificial colour standards are described for the estimation of urea, non-protein nitrogen, and proteins. The standards may also be used for the approximate estimation of blood sugar and haemoglobin.

Grateful acknowledgment is made to Drs. D. Beall and J. W. Clegg and to Mr. G. E. Delory for assistance with numerous comparisons between these procedures and those in routine use in this school.

\section{RFFERENCE}

Campbell W. R., and Hanna, M. I. (1937). J. biol. Chem., 119. 15.

Campbell, W. R., and Hanna, M. 1. (1937). J. biol. Chen

King, E. J., Haslewood, G. A. D., and Delory, G. E. (1937). Lancet, 1, 886.

* It is essential that the ether be peroxide-free; otherwise excess iodine may be liberated from the potassium iodide. The ether may be tested by adding $2 \mathrm{c} . \mathrm{cm}$. to a mixture of $2 \mathrm{c.cm}$. of water, $0.5 \mathrm{c} . \mathrm{cm}$. of potassium iodide, and $0.5 \mathrm{c} . \mathrm{cm}$. of sulphuric acid' If on shaking the mixture no perceptible yellow colour is present in the upper layer the ether is satisfactory for the test. In practice in the upper layer the ether is satisfactory for the test. In practice
only a very few samples of ether which had been stored in glass for a long time have proved unsatisfactory. 